\title{
Entre o varguismo e o florismo: a atuação da Frente Única Gaúcha no processo de isolamento político de Flores da Cunha
}

Between the varguism and florist: the performance of the United Gaucho Front in the political process of isolation of Flores da Cunha

Rafael Saraiva Lapuente* rafael.lapuente@acad.pucrs.br

Resumo: Apresento parte da pesquisa desenvolvida no Programa de Pós Graduação em História na PUCRS em nível de mestrado. Aqui, analisamos o papel da Frente Única Gaúcha (PL e PRR) no processo de isolamento político do governador Flores da Cunha no Rio Grande do Sul (1935-1937). A FUG, uma aliança constituída em função da Revolução de 1930, passou a ser um bloco político oposicionista a partir do momento em que se distanciou de Getúlio Vargas, rompendo por definitivo em função do apoio aos paulistas na Guerra Civil de 1932, esperando contar com o apoio de Flores da Cunha, então interventor, que não ocorre. Desmantelado o movimento, os frenteunistas passaram para o exílio e ostracismo, voltando ao cenário político depois da Lei da Anistia de 1934, agora como bloco de oposição a Getúlio Vargas e Flores da Cunha. No entanto, a partir de 1935, passou a dialogar com ambos, sobretudo na medida em que Getúlio Vargas e Flores da Cunha, de fieis aliados, passaram ao rompimento político e pessoal, com a resistência deste a qualquer movimento em direção a quebra da carta constitucional de 1934. Desta forma, constatamos que a FUG teve papel decisivo para ambos os lados em dissídio, realizando um acordo com Flores da Cunha em 1936 - modus vivendi - mas, a partir de 1937, teve papel preponderante para a queda do governador do Rio Grande do Sul, viabilizando o golpe do Estado Novo, duas semanas depois de sua renúncia. Para isso, dialogaremos com a literatura existente sobre o tema e com alguns arquivos pessoais e hemerotecas, assinaladas ao longo deste texto.

Palavras-chave: florismo, varguismo, Frente Única Gaúcha

Abstract: We try to present this work of the research developed in the Graduate Program in History at PUC at Masters level. Here, we analyzed the role of the United Front Gaucha (PL and PRR) in the political process of isolation of Flores da Cunha governor of Rio Grande do Sul (1935-1937). The FUG, an alliance formed due to the Revolution of 1930 becomes an opposition political bloc from the moment that distance Getulio Vargas, breaking a definitive due to the support of São Paulo in the Civil War of 1932, hoping to rely on Flores da Cunha support, then intervenor, which does not occur. Dismantled movement, the frenteunistas pass into exile and ostracism, returning to the political scene after the Amnesty Act of 1934, now as opposition bloc Getulio Vargas and Flores da Cunha. However, from 1935, would talk to them, especially in that Getulio Vargas and Flores da Cunha, of faithful allies, have political and personal disruption, with the strength of any movement toward the breakdown of the letter Constitution of 1934. Thus, we find that the FUG played a decisive role for both sides in labor agreement, making an agreement with Flores da Cunha in 1936 - modus vivendi - but, from 1937, would have the leading role in the fall of governor Rio Grande do Sul, enabling the Estado Novo coup, two weeks after his resignation. For this, we will work with the existing literature on the subject and some personal files and newspaper libraries, noted throughout this text.

Keywords: florismo, varguismo, United Gaucho Front

*Mestrando em História pela Pontifícia Universidade Católica do Rio Grande do Sul (PUCRS). Orientado por René Ernaini Gertz. 


\section{Introdução}

Objetivo responder aos seguintes questionamentos neste texto: como atuou a Frente Única Gaúcha no processo de isolamento político do governador Flores da Cunha? Qual seu grau de importância? Como se articulou e influenciou na "queda de braço" entre Getúlio Vargas e Flores da Cunha, que terminou com a renúncia deste poucas semanas do golpe que suplantou a carta de 1934? Essas incógnitas, que trago para o leitor na parte introdutória do texto, foram parte das "angústias" durante a escrita da dissertação do autor. Nela, gradualmente, este pesquisador passou a notar que a Frente Única Gaúcha, de grupo minoritário após a Guerra Civil de 1932, passou a ser a "fiel da balança" para Getúlio Vargas e Flores da Cunha. Isso na medida em que ambos, de grandes aliados, passam a se configurar em adversários que estiveram, por alguns momentos, próximos de estourar uma guerra civil entre o governo federal e o estado do Rio Grande do Sul.

Neste sentido, a importância deste artigo se justifica, primeiramente, pela escassez de estudos pela historiografia política sulina ao período que antecede o Estado Novo. Se, nos últimos anos, o Estado Novo no Rio Grande do Sul teve uma pluralidade considerável de pesquisas, a ponto de deixar a afirmação dada em 1991 por René Gertz (1991), de que havia pouca literatura sobre o período, relativamente obsoleta atualmente, o mesmo não se pode dizer acerca do período que engloba a "Revolução" de 1930 até 1937. Ainda há pouca literatura sobre o tema, seja sob a abordagem política, cultural, econômica ou administrativa. Nosso trabalho, portanto, segue no propósito de contribuir para conhecer melhor o período sob esta perspectiva regional.

Não apenas o período em que Flores da Cunha governou o Rio Grande do Sul estará em pauta neste texto, mas também procuro demonstrar que a Era Var- gas estará em estudo sob um recorte particular. Penso, aqui, como Janaína Amado (1990). Isto é, de que o estudo regional proporciona um olhar específico e particular sobre uma análise de cunho "nacional". Também destaco que, como Ana Luiza Reckziegel (1999; 2010; 2013), concordo que o estudo regional traz todas as questões pertencentes ao dito "estudo nacional", mas sua ótica traz a luz a especificidade, as diferenças e a multiplicidade. Mas, para ela, a História Regional só faz sentido se estiver dialogando com o macro, ou seja, a parte (região) e o todo (sistema que contém o recorte regional), Entretanto, ela destaca que isso não pode desembocar em análises globalizantes, pois o regional possui uma história própria, um conjunto de relações sociais delimitadas, um espaço de memória, de formação de identidades e de práticas políticas específicas, constituindo o regional menos um espaço físico, e mais um conjunto de relações e articulações em torno de identidades singulares. Até porque, como ela ressalta, o nacional é informado por uma perspectiva regional, enquanto este não pode ser significado sem a referência ao macro, visão semelhante à de Sandra Fernandéz (2007, p. 31), quando afirma que a história regional não propõe um novo tema ou objeto, mas "una nueva mirada, um nuevo acercamiento, un nuevo abordaje analítico" e que "la potencialidad de la representatividade del caso en la compreensión del todo, la interpretación de la particularidad para esbozar un plano general, la explicación de lo singular para la complejización de la totalidade".

Gostaria de concluir minha reflexão teórica sobre a abordagem regional, já bastante extensa, com Simon Schwartzman (1983). Este autor destaca a importância dos estudos regionais somados com a análise política. A política é vista por ele como um fenômeno essencialmente espacial, consistindo na organização de um poder central sobre um território e pela incorporação de diferentes regiões e setores a este centro, 
que é politicamente dominante. Essas regiões, porém, vivem em um processo de inter-relação política, e entram em jogo fatores que tem a ver com grupos sociais, classes e processos produtivos. Essa característica espacial, de grupos, gerações e diferenciações entre distintas áreas são importantes e devem ser levadas em conta, sob pena de não se compreender o processo político. Isso, para ele, é mais relevante em países territorialmente extensos, como é o caso do Brasil. Pois, se em um país pequeno e razoavelmente homogêneo há menos dificuldades para chegar-se à concepção de um “todo", já em uma federação ou em países geograficamente amplos não pode de maneira nenhuma ser entendido sem o componente regional colocado como foco central.

Utilizaremos algumas fontes primárias, consultadas tanto in locu quanto online. Os jornais consultados foram o Correio do Povo e Diário de Notícias, ambos consultados no Museu Hipólito da Costa, onde a coleção está relativamente completa. Além deles, por meio da Hemeroteca Digital da Biblioteca Nacional consultamos a coleção do periódico do PRL, A Federação. Entre as trocas epistolares, foram consultados o acervo pessoal de Raul Pilla, presente na UFRGS/ NUPERGS. Também foi usada a coleção pessoal disponível online de Getúlio Vargas, mantida pela FGV. Ainda que tangencialmente, o acervo pessoal de Sinval Saldanha, do Arquivo Historico do Rio Grande do Sul, foi usado neste trabalho. Todos estes materiais estão disponíveis publicamente para pesquisas.

Esclarecida parcialmente a parte teórica e as fontes utilizadas, a partir deste momento, subdividimos o texto em três partes. Rapidamente abordaremos o contexto em que se inseriam a FUG, o PRL, Flores da Cunha e Getúlio Vargas, tanto naquilo que concernia a política gaúcha como sua relação com o espaço macro. Posteriormente, abordaremos o retorno dos frenteunistas do exílio e sua atuação eleitoral e política, como oposição a Getúlio Vargas e Flores da Cunha, até a assinatura do modus vivendi. Depois, analisamos como este pacto funcionou, quais fatores foram determinantes para sua ruptura, e como a FUG passou a, gradualmente, se aproximar a Getúlio Vargas no embate contra o florismo, até a queda do governador, poucas semanas antes do Estado Novo.

\section{A FUG e o contexto}

A FUG é, basicamente, "filha" da "Revolução" de 1930, selando a união de dois partidos historicamente rivais e, na Primeira República, protagonistas de duas guerras civis. Essa união deixou o Rio Grande do Sul na singular condição de único estado unificado na campanha presidencial da Aliança Liberal e no movimento armado de 1930. No entanto, a frustração frenteunista com o governo provisório não demorou, tendo em vista que Getúlio Vargas, ao invés de subserviente ao seu partido, o PRR ${ }^{1}$, se mostrou independente da influência política regional, propiciando a ação dos tenentes e não favorecendo, diretamente, o Rio Grande do Sul. Isso, somado ao prolongamento do governo provisório e sua demora em constitucionalizar o país juntamente com a aproximação dos frenteunistas com a política paulista, fizera com que estes aderissem a Guerra Civil de 1932, partindo para o exílio e conspiração até 1934, quando a Lei da Anistia propiciou o retorno daqueles que pegaram em armas.

A adesão a esta guerra civil, que visava destituir Getúlio Vargas, ocorreu especialmente pelo fato de os frenteunistas contarem com a adesão do interventor do Rio Grande do Sul, Flores da Cunha. Contudo, isso acabou não acontecendo, com o interventor vendo-se

\footnotetext{
${ }^{1}$ Partido Republicano Rio-grandense.
} 
obrigado a fundar uma nova agremiação, o PRL, e terminar com a breve unificação que a FUG havia dado. Tachado de traidor, Flores da Cunha passaria a ser alvo não apenas da Guerra Civil, como também dos movimentos conspiratórios a partir daquele momento até a publicação da Lei da Anistia e retorno dos exilados para o território brasileiro com a restituição de seus direitos políticos. Com o retorno à legalidade e a cessão dos movimentos conspiratórios, a FUG passou a atuar comandando as oposições em nível nacional, tendo, como líder, João Neves da Fontoura. Sendo, portanto, um importante grupo político em nível nacional.

A FUG, inicialmente, faria oposição a Flores da Cunha, no plano regional, e a Getúlio Vargas dentro do espectro nacional. Isso no momento em que tanto Flores da Cunha como Getúlio Vargas eram importantes aliados, algo que mudaria a partir do momento em que o primeiro passa a ser governador constitucional, deixando de ser interventor, grosseiramente, uma espécie de "vassalo" do governo federal ao qual dependia desta lealdade para a manutenção no governo.

\section{Reaproximações, eleições, dissidências: a FUG entre o florismo e o varguismo}

A conjuntura política regional e nacional passaria por mudanças importantes entre 1934 e 1935, e a atuação tanto da Frente Única Gaúcha quanto do florismo seriam parte desse processo. Dentre estas transformações, ressaltamos, em especial, o processo de constitucionalização do país (1934) e do Rio Grande do Sul (1935). Em função disso, a FUG, por um lado, teria maior autonomia para agir como oposição regional a Flores da Cunha e nacional a Vargas, com o fim do caráter discricionário de ambos os governos, que teriam, neste momento, poderes partilhados com o Legislativo. Além disso, os frenteunistas possuíam a garantia constitucional para atuar como integrantes do bloco político de oposição em nível federal. Oposição "nacional" que, mesmo não sendo majoritária, tinha conquistado representação federal em 21 dos 22 estados da federação.

Já Flores da Cunha, a partir de sua eleição indireta em 15 de abril de 1935, deixaria de ser dependente de Vargas: era até então um interventor demissível, motivo pelo qual tinha seu cargo condicionado à lealdade ao governo central. Claro que, se a partir de agora ele não podia mais ser demitido, também já não teria a mesma influência dentro do governo central, como a própria composição ministerial havia indicado, relegando a participação gaúcha a um segundo plano. A tudo isso se somou uma imagem desgastada pela atuação "nos bastidores" dentro da Assembleia Nacional Constituinte, além de desentendimentos com Getúlio Vargas devido às suas intromissões em assuntos do Exército, da política federal, e interna de outros estados, motivo pelo qual ele "fechou a porta" para Flores da Cunha nesse quesito.

\section{A pacificação da política regional e as origens do Modus Vivendi}

Se Flores da Cunha buscou reunificar a política regional desde fins da Guerra Civil de 1932 e buscou, por outros momentos, dialogar com a FUG, mesmo no exílio para este fim (A FEDERAÇÃO, 25 maio. 1933; 30 abr. 1934), é a partir da anistia em que este assunto passa a ganhar fôlego. Em meio a uma virulenta campanha eleitoral de 1934, percebemos que, se por um lado o debate sobre a "pacificação" da política regional tem um tom muito mais hostil do que, efetivamente, dialógico, podemos afirmar que essa iniciativa viabilizou para que novas conversas fossem retomadas com um maior grau de seriedade no ano seguinte.

Em 1934, o mais marcante foi o chamado Discurso do Teatro Coliseu, ocorrido em meio à campanha eleitoral. Esta foi a primeira fez que o tema da 
"pacificação" política do Rio Grande do Sul foi abordado, em público, por um membro da FUG. No caso, pelo libertador Raul Pilla.

Tem-se falado, fala-se continuamente na pacificação do Rio Grande. Que espirito bem formado não a desejará? Mas, senhores, concedido que pudesse haver paz sem liberdade, paz sem garantias concedidas indistintamente a todos os cidadãos, paz sem a proscrição da violência e de distinções odiosas, seria esta pacificação digna do centenário farroupilha, que se pretende comemorar no ano próximo? Iriamos fazer a paz da submissão, a paz da subserviência para comemorar os grandiosos feitos daqueles heróis da liberdade? (CORREIO DO POVO, 20 set. 1934).

Raul Pilla também buscou amarrar o pronunciamento do interventor, utilizando suas declarações. Nesse sentido, relembrava que Flores da Cunha afirmou publicamente não ser um obstáculo ao "congraçamento da família rio-grandense e até se daria em holocausto a semelhante inspiração". Pilla prosseguiu, afirmando que “os homens da Frente Única também não serão obstáculo, porque não pleiteiam cargos, não desejam posições e aspiram apenas a que o Rio Grande possa ainda vir a dar ao país um exemplo de verdadeira democracia" (CORREIO DO POVO, 20 set. 934).

Rebatendo a assertiva de Pilla, Flores da Cunha se contradiria, pois agora rechaçava a ideia de renunciar, alegando que essa exigência, partindo da FUG, não passava de uma tentativa de escapar da provável derrota eleitoral, afirmando que "a renúncia que ela exige de mim é unicamente esta: que eu lhe dê uma saída para salvar-se". Também se defendeu das acusações de que seria "insincero quando afirmo que para bem da minha terra, para bem do Rio Grande, não hesitarei em me oferecer mesmo em holocausto". No meio dos debates, Pilla, no dia seguinte, rebateu, declarando que se o interventor estivesse disposto a "pacificar" o Rio Grande do Sul, renunciaria, e que a FUG não mudaria sua exigência. Internamente, a João Neves da Fontoura, ele dissera que a expectativa de permanência de Flores da Cunha por mais quatro anos era "simplesmente aterradora", e que só se pronunciava acerca da "pacificação" nos termos do Discurso do Teatro Coliseu, mencionando que, com a continuidade do florismo, analisava ser impossível participar do pleito municipal de 1935, sendo "materialmente impossível fazê-lo" (A FEDERAÇÃO, 25 set. 1934; CORREIO DO POVO, 26 set. 1934; ARP, doc. $\mathrm{n}^{\circ} 002 / 1279$ ).

Esse distanciamento se manteria até a virada do ano, onde novamente se tentou uma aproximação. No entanto, como podemos perceber, em 1934 o que a FUG exigia como "moeda de troca" era que Flores da Cunha renunciasse a uma possível candidatura a governador constitucional, o que lhe garantiria quatro anos no comando político e administrativo do Rio Grande do Sul. Isso, naquele ano, já prevendo a vitória do $\mathrm{PRL}^{2}$ para a escolha dos deputados constituintes estaduais, o que acabou ocorrendo efetivamente. A tentativa do ano seguinte, pouco antes da eleição indireta que definiu Flores da Cunha como governador constitucional, rondeou em torno da mesma exigência, o que foi rechaçado pelo PRL e pelo então interventor. A FUG, depois de nova negativa, buscou claramente desafiar as "intenções" de Flores da Cunha, propondo um projeto com 11 tópicos. Os onze pontos da FUG constituíam sugestões "informais" que, caso Flores da Cunha as seguisse sendo governador, não precisaria de um pacto de "pacificação", conforme alegavam os frenteunistas.

Nos pontos da ata de sugestões a Flores da Cunha, se nota que elas tinham como finalidade dar maior raio de ação para os frenteunistas nas próximas

\footnotetext{
${ }^{2}$ Partido Republicano Liberal.
} 
eleições contra o PRL, retirando o uso da coerção em favor do partido governista. Nesse sentido, como a violência esteve bastante presente nos dois pleitos, os primeiros itens propunham uma imediata reforma na polícia, com notória tentativa de retirar dela a influência partidária nos prélios eleitorais. Prova disso é que, dos 11 pontos, os cinco primeiros diziam respeito diretamente à necessidade de uma extensa modificação na estrutura policial, ou seja, quase metade da proposta versava sobre esse assunto, prevendo que a polícia perdesse o caráter partidário, instituindo um plano de carreira; que sua chefia fosse exercida por uma pessoa que possuísse atribuições pessoais, e que assegurassem isenção e imparcialidade no exercício da função; que fossem suprimidas as sub-chefaturas de polícia; prevendo a revisão nos quadros da polícia estadual e municipal, visando a destituir os funcionários denunciados ou pronunciados pela justiça, ou que fossem, por qualquer outra maneira, considerados inidôneos; e que fossem instaurados inquéritos para a repressão criminal de todos os responsáveis pelos atentados que a FUG alegava ter sofrido.

Já os tópicos seguintes propunham reformas na máquina administrativa do estado. Também teriam um viés político, embora não abordassem a questão policial. No sexto ponto, previa-se a redução da despesa pública com a supressão de gastos considerados desnecessários, além de prever a extinção de alguns privilégios fiscais; no sétimo, pautou-se por medidas para garantir o livre exercício das atividades eleitoras, e substituir autoridades que, direta ou indiretamente, tivessem sido responsáveis por crimes ou violências. Previa também a admissibilidade de funcionários públicos e promoções por meio de concurso e títulos, e não pelo critério partidário, além de readmitir os funcionários afastados por motivos políticos aos mesmos cargos anteriormente ocupado ou equivalente, somando na antiguidade o tempo em que ficaram afastados, tanto civis como militares. Nos últimos dois tópicos, a FUG defendia a proibição de quem exercia função pública em intervir no pleito eleitoral e na propaganda política, impondo suspensão administrativa e responsabilidade criminal para àquele que usasse do cargo para sugestionar, corromper, intimidar ou violentar qualquer eleitor, devendo ser destituído da função caso fosse demissível; e reivindicava que lhe fosse assegurada plena liberdade de imprensa, tribuna e reunião (ARP, doc. $\mathrm{n}^{\mathrm{O}}$ 002/1137).

Muitas dessas sugestões tinham indiscutível vínculo com as ocorrências desde 1932, como a readmissão de funcionários, ou a ampla liberdade de imprensa, tendo em vista a campanha de hostilidade contra o Correio do Povo pela A Federação, a proibição de suas vendas pelo diretor da Viação Férrea e o incêndio no jornal O Libertador, todos no pleito eleitoral de 1934. Também outros tópicos, como o sétimo, buscavam assegurar punição e investigação a crimes e perseguições anteriores ao pacto. $\mathrm{O}$ oitavo ponto buscava a inibição de uma atitude bastante comum, a da nomeação de partidários da facção política situacionista no estado. Afinal, essa prática atrelava o corpo de funcionários do estado a acompanhar o situacionismo, tornando-se seu aliado, e até mesmo servindo de informante, quando determinados funcionários não fossem apoiadores do PRL, sofrendo represálias, como demissões e transferências compulsórias, enquanto a penúltima cláusula anulava qualquer participação do funcionalismo nas questões políticas.

Praticamente, o único envolvimento com política partidária para o qual o funcionalismo teria permissão seria o direito ao voto. Terminaria desta forma o uso desse elemento para arregimentar eleitores, já que até mesmo por medo de demissão ou transferência, o voto e a participação no pleito em prol do partido situacionista era um costume comum. Ou seja, mesmo que a proibição abrangesse FUG e PRL, era este quem teria 
maior prejuízo, e não aquele. A única pauta que visava a alterações na estrutura governativa sem fins partidários era a sexta. Fato que, por si só, deixava claros os interesses frenteunistas, majoritariamente partidários, por trás dessa proposta.

De qualquer forma, a resposta de Flores da $\mathrm{Cu}-$ nha veio no dia seguinte, relativizando o documento entregue pela Frente Única. Sua réplica reenfatizava as propostas, que eram, em sua visão, apropriadas, e já postas em prática, segundo ele, pelo governo estadual. A reforma radical da organização policial, segundo Flores da Cunha, já era motivo de preocupação do governo, desde quando Florêncio de Abreu era o chefe de polícia estadual (1930), que desejava implantar a polícia de carreira, não tendo sido realizado devido às dificuldades financeiras por que, ainda segundo Flores, passava o estado, naquele momento. Defendia que o governo estadual já vinha comprimindo despesas, e que as atividades eleitorais, amparadas pela nova legislação dos velhos vícios, seriam protegidas por seu governo, assim como a reincorporação dos funcionários exonerados ou transferidos, que já estava prevista na nova carta estadual. Mas, no final, deixava a possibilidade para conversas no futuro, afirmando que os atos passados e os que estavam por vir iriam demonstrar "o quanto desejo contribuir para o desarmamento dos espíritos e para o estabelecimento de um período de paz duradoura, que permita ao povo bravo e generoso do Rio Grande do Sul uma existência tranquila e favorável aos surtos de sua evolução moral e material" (DIÁRIO DE NOTÍCIAS, 13 abr. 1935).

Como podemos perceber, Flores da Cunha não fechava a porta para a FUG, mas também se esquivava em dar uma resposta concreta e incisiva para atender a suas reivindicações. Por outro lado, a Frente Única não cedia em sua exigência. Foi assim que a questão da pa- cificação ficou morna, durante alguns meses. Mesmo que João Neves declarasse ao Diário de Notícias (11.04.1935) que "o acordo no Rio Grande do Sul [...] está sepultado, e bem fundo!", ele, na verdade, logo retornaria bem vivo na pauta dos partidos riograndenses. Paralelamente, enquanto Flores da Cunha era eleito governador, iniciava um processo de desgaste com Getúlio Vargas, ao se intrometer nas eleições dos estados de Santa Catarina e Pará, além de pressionar pela renúncia de Góis Monteiro do ministério da guerra, o que acaba conseguindo contra a vontade do próprio Getúlio Vargas (COUTINHO, 1956).

Isso, no entanto, não impediu que Flores da $\mathrm{Cu}$ nha, em uma reforma no secretariado, tentasse uma aproximação menos formal. Concatenado com uma série de reformas que seu governo iniciou no ensino estadual, Flores da Cunha convidava Raul Pilla, que era médico e professor, para assumir a pasta da Saúde e Educação Pública. Essa justificativa da administração florista estava intimamente ligada com o contexto dos anos 1930, quando, segundo Ângela de Castro Gomes (citado por ELÍBIO JR., 2006), foi marcado pela positivação da figura do técnico, imaginando-se que, com sua formação específica, de alto nível, ele poderia resolver problemas socioeconômicos através de um saber especializado, escolhido através de critérios ditos "impessoais". O teor do convite deixava claro que "não é feito ao político, e sim ao professor emérito, ao cidadão ilustre e digno, a cuja capacidade e virtudes eu desejaria confiar a tarefa de reorganizar e desenvolver os serviços de educação e saúde pública do Rio Grande do Sul”. Alegava, no final, que não possuía o desejo de contar com o apoio do $\mathrm{PL}^{3}$, nem exigiria mudança de orientação política de sua parte. Mas Pilla negaria o convite. Alegando que, mesmo não condizendo com nenhum compromisso político, era, para ele, impossível

\footnotetext{
${ }^{3}$ Partido Libertador.
} 
dissociar o médico e professor do político militante, questão que se agravava por ser presidente do Diretório Central do PL (DIÁRIO DE NOTÍCIAS, 14 jun. 1935).

A recusa ao convite para assumir o cargo foi elogiada pelos libertadores, demonstrando que esse tipo de proposta, dirigida a Raul Pilla, era descartada no PL. Ou seja, a ideia de convidar o professor e não o político militante, por parte de Flores da Cunha, não convenceu ninguém. Um telegrama recebido pelo líder do PL dizia compreender bem "o que significava o gesto do Flores", apreciando "grandemente tua resposta. Como acreditamos que nenhum libertador, numa tal emergência, pudesse aceitar para fazer parte do secretariado do Flores" (ARP, doc. nº 002/1144). Era lógico que Flores da Cunha, apesar de justificar sua proposta como não sendo de caráter político, buscava com ela uma aproximação com os frenteunistas, ainda que não fosse com um acordo formal, como a tentativa em fins de março havia sido. Mas, caso Pilla aceitasse, uma nova circunstância para as conversas em prol da pacificação política se abriria, como acabou ocorrendo, pois, apesar da recusa, haveria outras conversas entre FUG-PRL.

No entanto, as conversas entre FUG e Flores da Cunha não prosseguiram até, pelo menos, setembro de 1935. Entre agosto e setembro, entretanto, um importante desfecho dentro da política regional e nacional ocorrerá: o rompimento em definitivo entre Flores da Cunha e Getúlio Vargas. Este, que visita o Rio Grande do Sul em meio as festividades dos 100 anos da Guerra dos Farrapos, teria uma correspondência violada enquanto estava hospedado no Palácio do governo estadual por aliados de Flores da Cunha e divulgada na imprensa. O conteúdo desta seria uma "comprovação" de que Getúlio Vargas estava interferindo no pleito do estado do Rio de Janeiro, uma complicada eleição em que o governador do Rio Grande do Sul apoiava um candidato hostil ao governo federal. Junto a isto, suposta- mente teria havido um convite a Flores da Cunha para participar de um novo golpe, o que este teria negado (DIÁRIO DA CÂMARA DOS DEPUTADOS, 11 abr. 1953).

Em meio a esta conjuntura confusa, Raul Pilla elabora, junto com um jornalista carioca, uma fórmula parlamentarista para implantar em nível federal, visando a "pacificação do país". Esta fórmula ficou conhecida como Fórmula Santos-Pilla, que visava buscar uma “transformação dentro da ordem". Pilla, lendo o artigo do jornalista José Maria dos Santos, telegrafou para este, dando sugestões e mantendo intenso contato telegráfico, procurando viabilizar, dentro da FUG, a adoção deste projeto. O planejamento inicial de José Maria dos Santos era levar essa ideia para a Câmara dos Deputados, que contava, segundo ele, com importantes apoios. Convidava, ainda, Raul Pilla a ir para a capital junto com Flores da Cunha, para unificar os debates em um só lugar. (ARP, doc. $\mathrm{n}^{\circ}$ 002/1154).

No entanto, essa conversa teria ocorrido em 26 de setembro, bem no meio da crise fluminense, entre Vargas e Raul Pilla, propondo para aquele um acordo de "conciliação", que englobaria não apenas a FUG, mas todas as oposições. Este extenso documento previa, entre outros pontos, a criação da presidência do Conselho de Ministros. Como contrapartida, as oposições considerariam o Presidente da República acima das discussões políticas e parlamentares, evitariam criticar aos atos políticos, governamentais e administrativos posteriores a 1930, e repudiariam perturbações da ordem material, estendendo esses pontos também aos veículos de imprensa em que a oposição tivesse influência/controle, além de prometer acelerar o projeto da criação da presidência do Conselho de Ministros. Já em relação à maioria parlamentar, previa que ela abandonasse "toda controvérsia de pura oposição sobre os governos anteriores a 1930”, e o faria, também, com os 
veículos de imprensa com quem tivessem ligações. Ainda preconizava, como execução imediata, a revogação da Lei de Imprensa e da LSN, além de desmobilizar e extinguir todas as milícias ordinárias criadas depois de 1930, e reduzir os efetivos que tivessem sido aumentados depois daquele ano. Por fim, o acordo previa a demissão de todos os ministros, sendo substituídos pelos escolhidos do presidente do Conselho de Ministros, e que a aceitação e a permanência dos ministros ficariam condicionadas à maioria dos votos da Câmara dos Deputados (AGV, doc. nº GV c 1935.09.26/1).

Ou seja, o acordo proposto por Pilla, de cunho nitidamente parlamentarista, e que lembrava muitos pontos de seu projeto derrotado na Assembleia Legislativa estadual, imporia limites na concentração de poderes que o governo central tinha, submetendo o executivo ao parlamento. O presidente, que ficaria "acima" das "questões políticas", perderia o poder de nomear seus ministros, e partilharia seu poder com uma espécie de premiê, tipificado na presidência do Conselho de Ministros. Junto com a revogação da Lei de Imprensa e da LSN, o acordo deixava claro seu objetivo, que era amarrar a autonomia do poder executivo federal, descentralizando suas resoluções. Nesse sentido, o pacto agora proposto a Vargas era bem mais severo do que os 11 pontos da FUG propostos a Flores da Cunha, que pareciam mais limitar a máquina florista em períodos eleitorais do que "engessar" o poder do executivo, como a Fórmula Santos-Pilla propunha.

Vargas, portanto, eximindo-se de responsabilidades, criou uma junta composta de 26 pessoas para analisar o projeto de José Maria dos Santos e Raul Pilla. Pouco tempo depois, a mesma decidiu por sua reprovação, declarando não ser a Presidência do Conselho de Ministros e a reorganização do Ministério uma proposta legal, pois nos termos da constituição o poder executivo é “exercido pelo Presidente da República e passaria a ser exercido [sic] pelo presidente do Conselho de $\mathrm{Mi}$ nistros, a quem caberia a formação do novo ministério", nos termos da fórmula. Ainda destacava que a Constituição Federal considerava todos os ministros com a função de atuar como auxiliares do Presidente da República, e que constituiria sua competência particular "nomear e demitir os ministros de Estado; a responsabilidade dos ministros, pelos atos que subscreverem ou praticarem, pode ser conjunta com a do Presidente da República, mas independe da ação de qualquer outro membro do ministério". A única viabilidade, finalizava, era se ocorresse uma revisão constitucional, já que a carta de 1934 repelia o parlamentarismo preconizado nesta fórmula. Baseado nesses dados trazidos pela Junta, Getúlio Vargas respondeu a Raul Pilla, afirmando ser impossível "prosseguir no exame da fórmula proposta" (AGV, doc. $\mathrm{n}^{\circ} \mathrm{GV}$ c 1935.09.26/1). O interessante a se notar é que, através desse "grupo de estudos", Vargas conseguiu "terceirizar" a responsabilidade pela negativa ao acordo, eximindo-se desse encargo. Ou seja, a fórmula foi reprovada conforme desejava Vargas, mas aos olhos da FUG a recusa partia da Junta, e não do presidente. Enquanto isso, a relação entre Flores da Cunha e Getúlio Vargas apenas piorava.

Essa questão viabiliza para que Flores da Cunha buscasse "cooptar" a ideia de uma "pacificação" por meio da Fórmula Pilla, ancorado também no contexto pós-levante comunista. É dentro deste contexto que novos diálogos surgem, visando a formação do modus vivendi, de inspiração parlamentarista, e ancorado na Fórmula Pilla. Algumas conversas iniciam após a recusa de Vargas a Raul Pilla, onde pudemos notar, por meio do Arquivo Pessoal de Getúlio Vargas, uma intensa observação deste sobre o andamento das tratativas. Isso leva a crer que o presidente acompanhou com alguma preocupação o desfecho dessas tratativas, utilizando-se para isso de seu quarteto informante, composto por Viriato Vargas, Benjamin Vargas, Protásio Var- 
gas e Serafim Vargas, todos, por serem irmãos e sobrinho, de absoluta confiança do presidente.

No entanto, o modus vivendi, após estas contramarchas, é assinado em 17 de janeiro de 1936. Após algumas divergências, tendo em vista o debate levantado sobre se a fórmula era ou não constitucional, motivo ao qual Vargas havia justificado a negativa, que motivou até mesmo a elaboração de uma "fórmula republicana", a Fórmula Paim (DIÁRIO DE NOTÍCIAS, 29 jan. 1935). Mas, com a assinatura do acordo, este previa, em primeiro tópico, que os partidos teriam "completa autonomia e liberdade de ação política em tudo que não contrarie o disposto" no documento. Inicialmente, a deliberação já indicava que não havia acordos de ordem política, mantendo tanto FUG quanto PRL sua independência. $O$ segundo tópico tratava de um projeto de lei que seria enviado para a Assembleia Legislativa. Este, com oito artigos, que preconizavam, dentre outras assertivas, que os secretários ocupariam a posição de auxiliares diretos do governador, se reuniriam uma vez ou mais por semana, e lavrariam uma ata das reuniões. Assentava, no secretariado, a implantação de um presidente, que auxiliaria Flores da Cunha na sua organização, e coordenaria a atividade administrativa das secretarias, fiscalizando a execução do orçamento. Dava ao Legislativo estadual o direito de convocar qualquer secretário para prestar aos deputados informações sobre questões previamente determinadas, sendo a ausência sem justificativa considerada crime de responsabilidade. Por fim, o secretariado, depois de constituído, apresentaria seu programa de governo.

Já os partidos envolvidos concordavam em assinar um acordo com onze cláusulas, que estabelecia a luta em conjunto pela estabilidade das instituições, tendo em vista o levante comunista de novembro, na capital e no norte do país. Assegurava também a readmissão dos funcionários afastados ou transferidos por motivos políticos, contando o tempo de afastamento como antiguidade. Para isso, seria constituída uma comissão, formada por dois representantes frenteunistas e dois republicanos liberais, sob a presidência de um desempatador. A polícia seria reformada, criando o policiamento de carreira, com a vedação de critérios partidários para ocupar o cargo. O chefe de polícia seria escolhido entre o governador e o presidente do secretariado.

Já as autoridades policiais nos municípios em que a FUG havia vencido seriam nomeadas pelo prefeito. Na cláusula quarta, havia a previsão de apurar responsabilidades de funcionários que exercessem pressões partidárias sobre quaisquer cidadãos, por uma junta composta por membros da FUG e do PRL. Além disso, se efetuaria, com policiais considerados isentos, inquéritos com referência a fatos criminosos de natureza política cometidos no último pleito municipal; seriam criados concursos para promoção e admissão de funcionários, e haveria a garantia de direitos de imprensa, reunião, associação e propaganda. Destacando-se aqui que as únicas propostas sem caráter partidário previam suprimir os entraves fiscais que impedissem a circulação de riquezas, e privilégios à livre concorrência, a desenvolver as vias de comunicação, e a preservar o equilíbrio orçamentário. Por fim, o acordo finalizava condicionando o presidente do secretariado a contatar a FUG para designar o nome de seus representantes para fazer parte do governo, sendo estes mantidos apenas enquanto os partidos os confiassem nos cargos (CORREIO DO POVO, 18 jan. 1936). Aprovado como projeto de lei simples, a implantação da chefia do secretariado não implicou em uma reforma constitucional. As duas vagas que a oposição ocuparia no executivo seriam as secretarias da fazenda e da agricultura, que possuíam bastante relevância na administração estadual.

No entanto, o pacto não durou muito: já em fevereiro, algumas discórdias públicas sobre a sucessão 
presidencial conflitaram Maurício Cardoso, do PRR, e Flores da Cunha. Sendo que, em maio, uma grave crise no modus vivendi quase levou ao seu rompimento, envolvendo a política financeira de um município e a criação de um Corpo de Guardas da Polícia Militar, cujo projeto teve forte oposição entre alguns parlamentares da FUG, o que também motivou declarações em público do governador gaúcho, que insinuou que a atitude daqueles deputados teriam "interesses escusos" não declarados. Apesar das crises, de modo geral é possível afirmar que houve um apaziguamento na relação hostil entre Flores da Cunha e Frente Única. Claro que, uma das principais cláusulas costumeiramente invocadas era de que o modus vivendi era um pacto administrativo, e não político. Mas é possível dizer que, apesar disto, ele impactou em relativo apaziguamento entre as correntes partidárias. A aproximação, inclusive, levou a FUG negociar, com o PRL, a possibilidade de uma candidatura única no Rio Grande do Sul a presidência, com o nome de Raul Pilla, algo que foi rechaçado pelo fato de Flores da Cunha ter compromissos com o mineiro Antônio Carlos (AGV, doc. nº GV c 1936.07.08/1; PALDOLFI; GRYNSZPAN, 1997).

No entanto, se a aproximação da FUG com Flores trouxe, em tese, um apaziguamento, por outro lado provocou um intenso trabalho de Getúlio Vargas para desfazer o pacto, aliado com dissidências nos dois blocos políticos. Nota-se isso especialmente pelo fato de que, para muitos frenteunistas, configurava-se numa “ignóbil aliança” com aquele que os traiu em 1932, perseguiu no exílio e utilizou toda a máquina coronelística nos pleitos de 1933, 1934 e 1935. Por isso, é pertinente a colocação de Luciano Aronne de Abreu (2007, p. 112), quando este historiador afirmou que "pode-se dizer que o principal ganho dos partidos gaúchos com este acordo foi o aumento de poder obtido por cada um deles. Porém, ao contrário do que pretendiam seus sig- natários, esta união partidária não significou exatamente a pacificação do estado".

No PRL, essa dissidência seria, grosseiramente, explicada pelo "DNA" do partido: quando o Partido Republicano Liberal foi fundado, possuíam como elo apenas o fato de não concordar com a Guerra Civil e ficar ao lado de Getúlio Vargas e Flores da Cunha. Na medida em que este, como chefe do PRL, se aproximou da FUG, bloco que liderava as Oposições Coligadas, isso soava dentro do partido como uma "guinada" contra o governo federal. E muitos de seus membros estavam no PRL justamente por apoiar Vargas. Tanto que, imediatamente, o irmão do presidente, o deputado estadual Benjamin Vargas, passou a ser instruído para organizar a Dissidência Liberal, que deveria fazer oposição ao comando de Flores da Cunha. Vargas, dentro da FUG, passaria a estimular uma "dissidência frenteunista", buscando rebelar um núcleo de membros da aliança contra o pacto.

$\mathrm{Na}$ pesquisa documental, fica claro que, dentre os aliados de Vargas nesse trabalho, estava o exministro Maurício Cardoso, deputado estadual pelo PRR, e o jovem vereador Alberto Pasqualini, do Partido Libertador. Este núcleo na FUG teria importante papel no isolamento político de Flores da Cunha, formandose uma "resistência" contra a aproximação ao florismo. Um telegrama de um dissidente liberal, Loureiro da Silva, expunha bem aquele contexto. Dissera ele que "das mortes e composturas aos abraços públicos mediou pouco tempo", o que "só podia trazer, como trouxe, uma profunda desilusão e descrédito", desejando o deputado do PRL que Flores da Cunha não se jogasse em oposição a Vargas (AGV, doc. nº GV c 1936.01.28/2; AGV, doc. ${ }^{\circ}$ GV c 1936.02.02).

Quando ocorreu a crise final do modus vivendi, esta foi rondeada, nacionalmente, pelo octálogo, um projeto proposto pela FUG para a escolha de um candi- 
dato consensual para a sucessão presidencial, ao qual teve algumas objeções de Flores da Cunha e Getúlio Vargas, pela organização militar florista, tendo em vista que o governador do estado se preparava para deflagrar uma guerra civil contra o governo federal ou, na menor das hipóteses, resistir a uma intervenção federal, tendo em vista o enorme desgaste com o Catete.

Além disso, o fato principal foi a eleição de um deputado para a Mesa Diretora da Assembleia Legislativa, ao qual Flores da Cunha escolheu um candidato como questão fechada. No entanto, a Frente Única Gaúcha, juntamente com alguns deputados da nascente Dissidência Liberal, votaram em um candidato distinto, derrotando Flores da Cunha e, a partir dali, deixando o governador do estado com minoria no parlamento, fato inédito, até então, na história do Rio Grande do Sul republicano. Também se desenhava a aliança entre a Dissidência Liberal e a FUG, cuja qual se manteria até o golpe do Estado Novo. A FUG, por sua vez, renunciaria aos cargos ocupados no secretariado do governo do estado. Dava-se a maior crise política no Rio Grande do Sul desde a Guerra Civil de 1932.

\section{A FUG e a aproximação com Getúlio Var- gas: a busca pela derrocada do florismo}

A partir do momento em que o modus vivendi foi rompido, a FUG passou a fazer ferrenha oposição a Flores da Cunha. No entanto, cabe a reflexão: se parte dos frenteunistas se opuseram a uma aliança com Flores da Cunha, como poderiam, agora, se aproximar de Getúlio Vargas, sendo que foi contra este que pegaram em armas em 1932, e não contra aquele? Fato é que o rompimento do modus vivendi trouxera algumas dissidências, como a de Lindolfo Collor, ex-ministro de Vargas e membro do PRR, e de um pequeno núcleo socialista do PL (NOLL, 1980), sendo que apenas o primeiro pode-se dizer que trouxe algum reflexo, com a cooptação de um deputado para o seu novato Partido
Republicano Castilhista, fundado em maio de 1937 e de brevíssima duração. Isso porque, se FUG e Dissidência possuíam maioria no legislativo a partir de outubro de 1936, deve ser destacado o fato de esta ser de somente um deputado na maior parte do tempo. Ou seja, o controle do legislativo era bastante sensível.

Também se deve destacar que o octálogo, mencionado acima, foi recusado pelas Oposições Coligadas, fato que motivou a retirada da FUG do núcleo de oposição. Isso explica, também, sua aproximação com o varguismo. Isolada como oposição no Rio Grande do Sul, e fora do maior bloco parlamentar em nível nacional, este que já sofrera perseguições por parte do governo federal sob justificativa de combater o comunismo, restava aos frenteunistas ou se aliar com Getúlio Vargas ou entrar em um ostracismo somente menor do que aquele que os levou para o exílio no pós-1932.

Efetivamente, a FUG terá papel importante para impor derrotas a Flores da Cunha no parlamento. Uma verdadeira "caça as bruxas" se dá no legislativo estadual: desde a investigação sobre contas, pedidos de esclarecimentos e rejeição de vetos do governador. O nó político é tamanho que até Oswaldo Aranha, em um breve retorno ao Brasil, consegue uma trégua parlamentar em meio ao recesso, apelando para Getúlio Vargas instruir os dissidentes a interromperem com os ataques e escolherem uma candidatura neutra para presidência da casa, algo prontamente negado (VARGAS, 1995).

É verdade que, por outro lado, Vargas trabalhou para que fosse garantida a manutenção da maioria no parlamento em 1937, por meio dos dissidentes e frenteunistas. O maior trunfo, neste sentido, foi o pedido de transferência do Estado de Guerra, que era de direito ao governador do estado, para o comandante da III Região Militar, subordinado a Getúlio Vargas. Em 25 de abril, no mesmo dia em que os dissidentes lançaram seu manifesto contra Flores da Cunha, o "ataque duplo" con- 
tou com o pedido de transferência do estado de guerra para uma pessoa alheia à política regional e de confiança do Catete pela Assembleia Legislativa, alegando insegurança por mobilizações clandestinas com objetivos desconhecidos ao redor da Casa, impedimento dos trabalhos da imprensa, preparativos bélicos organizados pelo executivo estadual e infestação de "criminosos ilegalmente libertados", alegando ser necessário para manter o equilíbrio entre o executivo e o Legislativo. (DIÁRIO DE NOTÍCIAS, 29 abr. 1937). Certamente, a sincronia entre o manifesto e a requisição foi resultado de uma articulação conjunta entre os dissidentes liberais, o executivo federal e o Exército, atacando o florismo politicamente através da imprensa e ameaçando sua base militar. Alguns frenteunistas, por outro lado, defendiam explicitamente uma intervenção militar, como Alberto Pasqualini, que acreditava ser esta a única solução plausível para derrubar Flores da Cunha, a quem ele definia como um "subproduto da espécie humana". (AGV, doc. $\mathrm{n}^{\mathrm{o}}$ 1937.04.00/1/ AGV, doc. $\mathrm{n}^{\mathrm{o}}$ 1937.04.00/2).

Aqui, é importante ressaltar que, na medida em que Vargas consegue, com o apoio da FUG, controlar Flores da Cunha politicamente, suas atenções se voltam para o terreno militar e a desarticulação da força armada florista, o que, em parte, é um assunto que os frenteunistas e dissidentes liberais pouco participam, onde a questão ficou mais envolta a Góis Monteiro, Lucio Esteves e o Marechal Eurico Dutra. Por outro lado, isso não significou que os frenteunistas estivessem totalmente alheios. Embora, é bem verdade que passaram a ter menos trabalhos. Ocorreria apenas uma dissidência na FUG em 1937 de maior relevo, em função da sucessão presidencial. Se Flores da Cunha apoiou Armando Salles, os frenteunistas apoiaram, como consequência lógica, o candidato do governo, José Américo de Almeida. No entanto, alguns membros do PL não admitiram a hipótese de se apoiar, explicitamente, um candidato varguista, que contrapunha o armandismo, do Partido Constitucionalista, partícipe da Guerra Civil de 1932. Este núcleo, denominado de Ação Libertadora, foi a mais forte cisão na FUG desde o final do modus vivendi, e alegavam que a Frente Única sofria de "cegueira facciosa, odiosidade vesga, estultice política", pois alegavam que, se essa candidatura "nos fizer jus a apoio, que importa que a prestigiem, também, nossos adversários no âmbito estadual? Antes, isso nos deve regozijar, pois lhe aumentará as probabilidades de vitória" (DIÁRIO DE NOTÍCIAS, 16 maio. 1937).

Porém, mesmo com a adesão de um deputado estadual, seguiram os oposicionistas controlando o parlamento. Pois vale destacar que, da pouca documentação encontrada da Ação Libertadora, nota-se claramente que ela não foi constituída apenas pelo apoio ao armandismo. Foi, também, uma aliança política com o governo estadual, embora não declarasse isso abertamente. Ao menos em um destes telegramas, Felipe Portinho pedia emprego a um membro da Ação Libertadora e verbas para uma passagem de aviação ao Rio de Janeiro para a campanha eleitoral. Pedido atendido, segundo as anotações a próprio punho com a assinatura de Flores da Cunha. Além disso, chamou a atenção de Raul Pilla o aporte financeiro do grupo, afirmando que "por toda a parte escirtórios [sic] eleitorais luxuosamente instalados, com funcionários pagos à razão de seiscentos a oitocentos mil reis mensais" (APSS/BM,

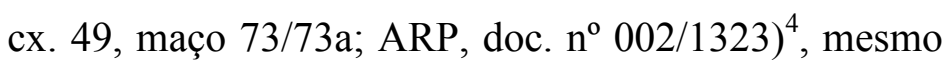
que ele costumeiramente tachasse o grupo de Portinho como pequeno e irrelevante, o que não nos parece totalmente verdadeiro, pois a mínima cizânia poderia colo-

\footnotetext{
${ }^{4}$ O outro telegrama, de Gabriel Pedro Moacyr, é menos claro. O autor diz somente apresentar um "companheiro da UDB", e Flores da Cunha respondeu a mão: "dizer o que pretende", o que não deixa de sinalizar essa proximidade. Cf. APSS/BM, 09.10.1937, AHRGS, cx. 49, maço 73/73A.
} 
car a FUG em situação de desvantagem na Assembleia Legislativa.

No entanto, ainda que assegurada, por parte da FUG, o estancamento dessa cizânia, nos momentos finais do governo Flores da Cunha, o deputado Maurício Cardoso esboçou um plano de impeachment pela via parlamentar. Até porque havia, entre alguns frenteunistas, a exigência de que a derrubada do governador fosse pela via constitucional. Entre eles, especialmente, Raul Pilla. Ele achava que o combate ao florismo deveria se dar pela Assembleia Legislativa, e se houvesse uma intervenção, vista em alguns momentos por ele como uma "necessidade", ela deveria "ter fundamentos legais, não tanto por nós, como principalmente pelo governo federal, cuja estabilidade poderia comprometerse", afirmando recear "não tanto o que passou, como o que há de vir. A não ser que se pretenda dar um golpe de estado no país, coisa com a qual eu nunca concordaria, não sei como se há de levar o caso, a não ser constitucionalmente" (ARP, doc. $\mathrm{n}^{\mathrm{o}}$ 002/1318), mostrando certo distanciamento de Vargas, postura que manteria até o Estado Novo.

É nessa conjuntura que vai surgir à ideia do impeachment. Dissidentes e frenteunistas, inicialmente, formaram grupos para analisar as contas do governo Flores da Cunha, para iniciar ataques à administração, e, segundo Maurício Cardoso, responsabilizar o governador e seu secretariado. Mesmo que Cardoso reconhecesse a dificuldade de se efetuar o impeachment, acreditava que o processo deixaria “a opinião pública [...] plenamente orientada", advindo "incontestáveis vantagens no terreno eleitoral para a próxima campanha", e entendia que "o impeachment será o primeiro passo para o problema da intervenção, que, então, poderá ser posto e resolvido no campo estritamente constitucional" (AGV, doc. no GV c 1937.08.00). Contudo, esse plano "vazou" para a imprensa. O Correio do Povo no- ticiou ter descoberto uma denúncia de Maurício Cardoso contra Flores da Cunha (CORREIO DO POVO, 24 e 27 ago. 1937), enquanto se iniciou um debate para esclarecer a legalidade do ato, pois não havia, na Constituição Estadual, a regulamentação de um impeachment, processo que seria inédito na história do Rio Grande do Sul republicano.

Flores da Cunha agiu. Antes de um processo desse teor circular na Assembleia Legislativa, o deputado classista Alexandre Rosa renunciou ao cargo. Ele, que estava com o bloco antiflorista na casa, cedeu lugar a um suplente ligado ao florismo, Moacyr Godói Ilha, o que, temporariamente, deixou oposição e governo em situação equivalente, pois o novo parlamentar não assumiu logo por estar enfermo (CORREIO DO POVO, 05 set. 1937). Mas logo devolveria a maioria numérica ao governo estadual, inviabilizando a aprovação de projetos hostis ao governo, como um impeachment, e de rejeitar os vetos do executivo estadual. Esse fato foi encarado pela ala antiflorista como fruto de um suborno de Flores da Cunha ao deputado renunciante.

E as preocupações chegaram a Getúlio Vargas (1995, p. 561). Em seu Diário, ele anotou: “isso acarretaria profunda modificação política, pois o Flores voltaria a ter maioria na referida Assembleia. Providenciei para que seguisse para lá, de avião, no próximo domingo, seu amigo dr. Miguel [Tostes], a ver se o demove dessa atitude", afirmando que "há suspeitas de um caso de suborno". Efetivamente, não é infundada a hipótese de suborno. Além de Benjamin Vargas achar difícil reconquistar a maioria na Assembleia Legislativa por Flores da Cunha estar "distribuindo dinheiro a rodo e cuidando [de] seus deputados", deve-se levar em conta que o governador sabia dos planos para colocar um impeachment em votação. Isso ficou explícito na edição de 3 de setembro de A Federação, que comentava sobre a recuperação da maioria no Legislativo pelo governo e 
a inviabilidade desse projeto ser apresentado. Já o então deputado classista Carlos Santos admitiu, anos depois, que "foi tremenda a caça a este último voto que faltava, meus amigos e irmãos!". Como ficou ao lado de Flores da Cunha, Carlos Santos disse que sofreu intimidações e tentativas de suborno vindas do bloco pró-Vargas, com ameaças de, até, sequestro e assassinato, caso não mudasse de posicionamento, ganhando segurança particular designada por Flores da Cunha (AGV, doc. $n^{\circ} \mathrm{GV}$ c 1937.09.01; A Federação, 03.09.1937; SANTOS, 1983).

A atuação da FUG, garantindo a supremacia política, viabilizou para que Getúlio Vargas concentrasse sua ação no campo militar para isolar Flores da $\mathrm{Cu}$ nha, pelo menos, desde abril de 1937. Desta forma, sua aliança com o núcleo da Dissidência Liberal viabilizou para que Vargas, em um verdadeiro "jogo de xadrez" contra seu antigo aliado que existira desde o momento em que ambos romperam relações em agosto de 1935, se tornou uma peça importante e disputada entre o varguismo e o florismo. Até porque, a união do Rio Grande do Sul contra Getúlio Vargas não era bem-vista pelo presidente.

Flores da Cunha, por outro lado, se tentou juntar a política rio-grandense para fortalecer seu governo nos embates contra o governo federal, acabou sendo atado pelo "nó" dado por setores frenteunistas, além de sua própria inabilidade política, ao mobilizar corpos provisórios, o que causou o descontentamento da FUG.
Grosso modo, os frenteunistas, que buscaram usar o modus vivendi como uma espécie de test drive para aplicar a Fórmula Pilla em nível nacional, acabaram também vendo a obsolescência desta aliança com o florismo, na medida em que, de janeiro até o rompimento, em outubro, notamos que Getúlio Vargas sempre procrastinou a decisão de adotar a fórmula parlamentarista. Porém, este fato nunca redundou, efetivamente, em um total afastamento da FUG com o governo federal. Este, por sua vez, ao estimular o octálogo, demonstrou para a FUG que estava disposto a uma fórmula "pacificadora" distante do parlamentarismo. Enquanto as oposições e o florismo rejeitavam parcialmente o octálogo, isso dava a entender, aos olhos do frenteunismo, de que Vargas esta disposto a negociar, "lavando as mãos", diferentemente daqueles que faziam objeções.

Por fim, elucidamos ao leitor não apenas o papel ambíguo da FUG, mas como ela passou de um grupo minoritário e oposicionista nas esferas federal e estadual para um núcleo político indispensável. Em parte, inclusive, teve papel importante para a implantação do Estado Novo. Não apenas por aceitar o golpe de estado, mas porque a resistência militar de Flores da Cunha era o principal entrave para isso. Na medida em que, em outubro, ele se viu isolado militar e politicamente, não havendo outra opção a não ser renunciar e se dirigir para o exílio, a FUG viabilizou a intervenção federal no estado antes mesmo do Estado Novo. Este, por sinal, seria outorgado cerca de três semanas depois de Flores da Cunha desembarcar em Montevidéu. 


\section{Referências bibliográficas}

ABREU, Luciano Aronne de. Um olhar regional sobre o Estado Novo. Porto Alegre: Edipucrs, 2007.

AMADO, Janaína. História e região: reconhecendo e construindo espaços. In: SILVA, Marcos A. da (dir.). República em Migalhas: história regional e local. São Paulo: Marco Zero, 1990.

COUTINHO, Lourival. O General Góes Depõe...Rio de Janeiro: Editora Coelho Branco, 1956.

ELÍBIO JÚNIOR, Antônio Manoel. A construção da liderança política de Flores da Cunha: Governo, história, política. Tese (Doutorado em História), Unicamp, Campinas, 2006.

FERNÁNDEZ, Sandra. Introducción. In: FERNÁNDEZ, Sandra (comp.). Más allá de lterritorio: la historia regional y local como problema. Discusiones, balances y proyecciones. Rosario: Prohistoriaedicciones, 2007.

GERTZ, René. Estado Novo: um inventário historiográfico. In: SILVA, José Luiz Werneck da. (org.). Feixe e o prisma: o autoritarismo como questão teórica e historiográfica. Rio de Janeiro: Zahar, 1991.

NOLL, Maria Izabel. Partidos e política no Rio Grande do Sul (1928-1937). Dissertação (Mestrado em Ciência Política) - Universidade Federal do Rio Grande do Sul, Porto Alegre, 1980.

PANDOLFI, Dulce; GRYNSZPAN, Mario. Da revolução de 30 ao golpe de 37: a depuração das elites. Revista de Sociologia e Política. Paraná, v. 2, nº 9, jul/dez 1997.

RECKZIEGEL, Ana Luiza Setti. Apresentação. In: BATISTELLA, Alessandro et al (orgs.). Fazendo História Regional: política e cultura. Passo Fundo: Méritos, 2010.

jun/dez-1999.

História Regional: dimensões teórico-conceituais. História: debates e tendências. Passo Fundo, n. 1, v. 1,

O historiador e a história regional. In: REICHERT, Emannuel Henrich; SILVA, Amanda Siqueira da; TEIXEIRA, Anderson Mattos (orgs.). Desvendando a história regional: novas pesquisas. Passo Fundo: Editora Méritos, 2013.

SANTOS, Carlos. Depoimento. In:SIMPÓSIO sobre a Revolução de 30. Porto Alegre: ERUS, 1983.

SCHWARTZMAN, Simon. A revolução de 30 e o problema regional. In: SIMPÓSIO sobre a Revolução de 30. Porto Alegre: ERUS, 1983.

VARGAS, Getúlio. Diário. Rio de Janeiro/São Paulo: FGV/Siciliana, 1995, v. II.

\section{Acervos e arquivos:}

A Federação - Hemeroteca Digital da Biblioteca Nacional.

Correio do Povo - Museu de Comunicação Social Hipólito José da Costa.

Diário de Notícias - Museu de Comunicação Social Hipólito José da Costa.

Arquivo Raul Pilla - NUPERGS/UFRGS.

Arquivo Getúlio Vargas - CPDOC/FGV.

Arquivo Sinval Saldanha/Borges de Medeiros - AHRGS.

BRASIL. Congresso Nacional. Câmara dos Deputados. Diário da Câmara dos Deputados. Rio de Janeiro. Ano VIII, $\mathrm{n}^{\mathrm{o}}$ 69, 11.04.1953, p. 2642. Disponível em: <http://imagem.camara.gov.br/Imagem/d/pdf/ DCD11ABR1953.pdf\#page=>. Acesso em: 25 jul. 2015. Discurso do deputado federal Flores da Cunha. 